\title{
CORREÇÃO DE TERRENO PARA DADOS DE AEROGRADIOMETRIA GRAVIMÉTRICA 3D-FTG NO QUADRILÁTERO FERRÍFERO, MINAS GERAIS, BRASIL
}

\author{
Marco Antonio Braga ${ }^{1}$, Dionísio Uendro Carlos², Rodrigo Rocha Sousa ${ }^{3}$, \\ Henry Galbiatti ${ }^{*}$ e Tiago de Almeida ${ }^{5}$ \\ Recebido em 26 maio, 2009 / Aceito em 16 março, 2010 \\ Received on May 26, 2009 / Accepted on March 16, 2010
}

ABSTRACT. The aim of this research is to show the application of terrain correction to 3D-FTG data at Baú-Gandarela, Quadrilatério Ferrífero region at Minas Gerais State, Brazil. For this purpose we have used different digital terrain models with distinct resolutions (SRTM versus lidar).

Keywords: terrain correction, gravity gradiometry, digital terrain model.

RESUMO. 0 presente trabalho tem 0 objetivo de apresentar a aplicação da correção de terreno aos dados de aerogradiometria gravimétrica 3D-FTG na região do Baú-Gandarela no Quadrilátero Ferrífero, Minas Gerais, Brasil. Para isso utilizamos modelos digitais de terreno com resoluções distintas (SRTM versus laser). Os dados de aerogradiometria gravimétrica corrigidos com o modelo digital de terreno do SRTM causaram imprecisões no resultado da componente $T_{z z}$ (representa a geologia), acarretando erros na interpretação geológica, na avaliação do potencial mineral da área e nas ações de pesquisa e exploração. 0 modelo digital de terreno a laser forneceu uma melhor resolução aprimorando os aspectos anteriormente citados.

Palavras-chave: correção de terreno, aerogradiometria gravimétrica, modelo digital de terreno.

Vale, Gerência de Exploração Mineral de Ferrosos - GAEMF, Av. de Ligação 3580, Águas Claras, Centro de Tecnologia de Ferrosos, 34000-000 Nova Lima, MG, Brasil. Tels.: +55(31) 3215-4200; ${ }^{*}+55(31)$ 3215-4278 - E-mails: ${ }^{1}$ marco.antonio.braga@vale.com; ${ }^{2}$ dionisio.carlos@vale.com; ${ }^{3}$ rodrigo.rocha.sousa@vale.com; 4henry.galbiatti@vale.com; 5 almeidageo@yahoo.com.br 


\section{INTRODUÇÃo}

Uma das maiores contribuições para as componentes do sinal do gradiente da gravidade é originada pelo terreno. Se a topografia e a densidade forem conhecidas, o gradiente de gravidade dessa superfície pode ser calculado (componentes sintéticas). Um modelo digital de terreno (MDT), Figura 1, pode ser criado contendo dados de posição e pode ser utilizado para facilitar a pesquisa. Após o cálculo das componentes sintéticas, pode-se subtrair dos gradientes da gravidade medidos (Fig. 3), revelando anomalias de gradiente da gravidade que não são relacionadas à topografia, mas a prováveis corpos potenciais de minério.

\section{MODELO DIGITAL DE TERRENO}

\section{Função de Green}

A função de Green descreve o comportamento dos gradientes de gravidade de acordo com a distância ou posição. 0 potencial gravitacional numa posição $r$ devido a uma fonte pontual é dada pela função de Green para 0 potencial gravitacional (Wolobah, 2007), por:

$$
G(r)=-\frac{\gamma}{r}
$$

onde:

$\gamma=$ constante de gravitação universal;

$r=|r|=\left(x^{2}+y^{2}+z^{2}\right)^{\frac{1}{2}}$.

Substituindo $r$ em (1) e derivando duas vezes em $z$, obtemos:

$$
T_{z z}=\frac{\partial^{2} G(r)}{\partial z^{2}}=-\frac{\gamma}{r^{3}} \cdot \frac{\left(3 z^{2}-r^{2}\right)}{r^{2}} .
$$

Aplicando a mesma ideia a cada uma das variáveis $x, y$, obtemos as demais componentes:

$$
\begin{aligned}
& T_{x x}=\frac{\partial^{2} G(r)}{\partial x^{2}}=-\frac{\gamma}{r^{3}} \cdot \frac{\left(3 x^{2}-r^{2}\right)}{r^{2}} \\
& T_{y y}=\frac{\partial^{2} G(r)}{\partial y^{2}}=-\frac{\gamma}{r^{3}} \cdot \frac{\left(3 y^{2}-r^{2}\right)}{r^{2}} \\
& T_{x y}=\frac{\partial^{2} G(r)}{\partial x \partial y}=-\frac{\gamma}{r^{3}} \cdot \frac{3 x y}{r^{2}} \\
& T_{x z}=\frac{\partial^{2} G(r)}{\partial x \partial z}=-\frac{\gamma}{r^{3}} \cdot \frac{3 x z}{r^{2}} \\
& T_{y z}=\frac{\partial^{2} G(r)}{\partial y \partial z}=-\frac{\gamma}{r^{3}} \cdot \frac{3 y z}{r^{2}}
\end{aligned}
$$

Com base nesse desenvolvimento, os modelos sintéticos das componentes do tensor de gradiente da gravidade foram cons- truídos a partir do modelo digital de terreno da região do BaúGandarela (Fig. 2).

Os cálculos para remover o efeito do terreno requerem um conhecimento detalhado da superfície topográfica local e da densidade na região da leitura do gradiente da gravidade (veja Eq. 8).

Em geral, a resposta 3D do gradiente da gravidade da topografia é calculada de forma que possa ser subtraída dos dados de gradiente da gravidade efetivamente coletados em campo. Essa subtração gera as anomalias corrigidas ou anomalias Bouguer. Com os dados de FTG, primeiramente, modelamos as anomalias que são as altas frequências ou curtos comprimentos de onda, produzidos por fontes rasas que fazem parte da zona de interesse de prospecção. Os sinais de alta frequência das anomalias podem interferir com os sinais de baixa frequência das anomalias que são geradas presumivelmente por fontes mais profundas, porém dentro de uma zona de interesse para a exploração. Assim, o sinal do gradiente da gravidade gerado pela geologia conhecida é removido das anomalias residuais geradas pelas altas frequências. Com a remoção das anomalias das fontes mais rasas, as anomalias dos grandes comprimentos de onda geradas por fontes mais profundas, ficarão mais aparentes.

As medidas de gradiente da gravidade devem ser realizadas levando-se em consideração as dimensões do alvo que se deseja mapear, topografia da região e contraste de densidade. Quando um terreno apresenta densidades variadas, as medidas de gradiente da gravidade observadas correspondem a essas densidades diferentes. Assim, ao executar o processamento e a interpretação dos dados, 0 sinal do gradiente da gravidade e 0 sinal do terreno precisarão ser analisados e processados usando diferentes valores de densidade.

\section{MATERIAIS E MÉTODOS}

A pesquisa aqui desenvolvida tem 0 intuito de apresentar as diferenças nos resultados calculados das componentes do tensor de gradiometria gravimétrica e suas implicações na interpretação geológica destes dados quando são utilizados modelos digitais de terreno com resoluções distintas. A área em estudo compreende os municípios de Barão de Cocais e Santa Bárbara (Fig. 4), situados na região do Quadrilátero Ferrífero, no estado de Minas Gerais. A topografia é acidentada e montanhosa ( $\min \sim 770 \mathrm{~m}$, max $\sim 1660 \mathrm{~m}$, média $\sim 1120 \mathrm{~m}$ ). Os modelos digitais de terreno utilizados para este estudo foram o SRTM (Shuttle Radar Topography Mission) coletado pela National Aeronautic and Space Administration - Nasa - (Farr et al., 2007) e o modelo a laser adquirido pela Vale em 2007. 


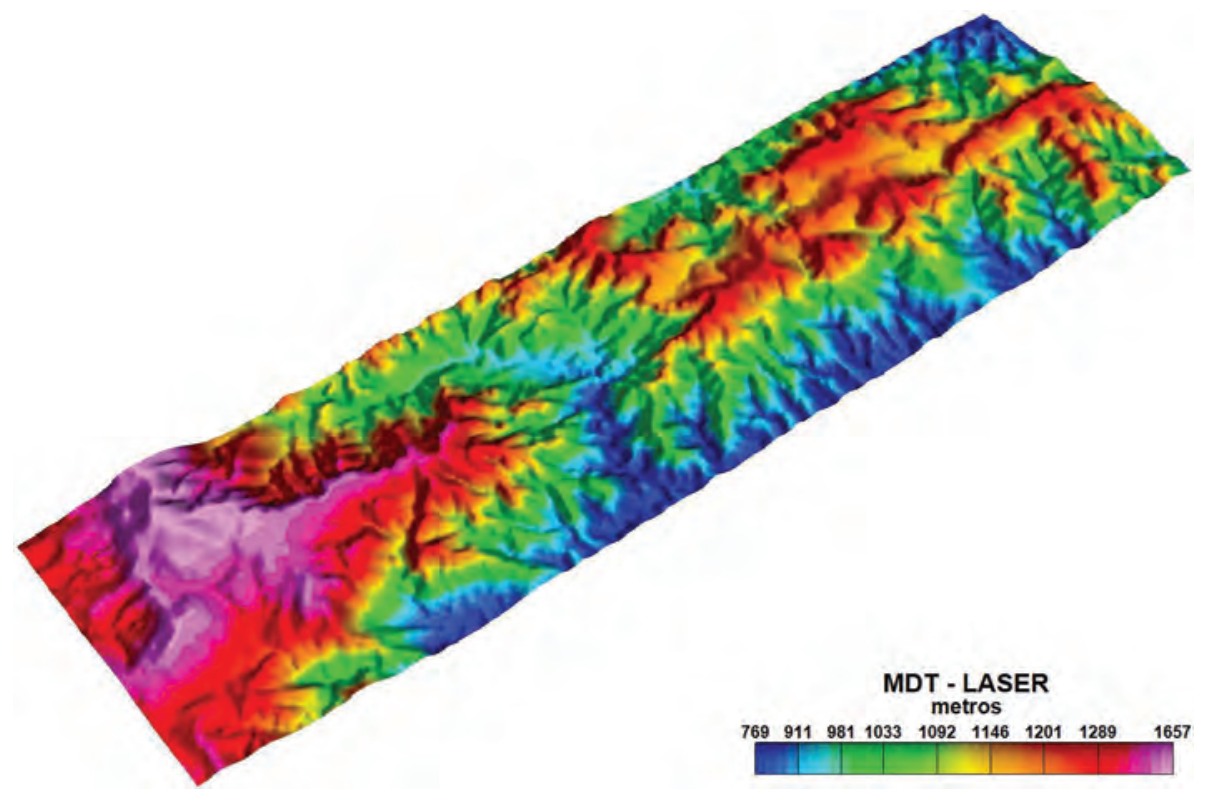

Figura 1 - Modelo digital de terreno (MDT) da região do Baú-Gandarela.

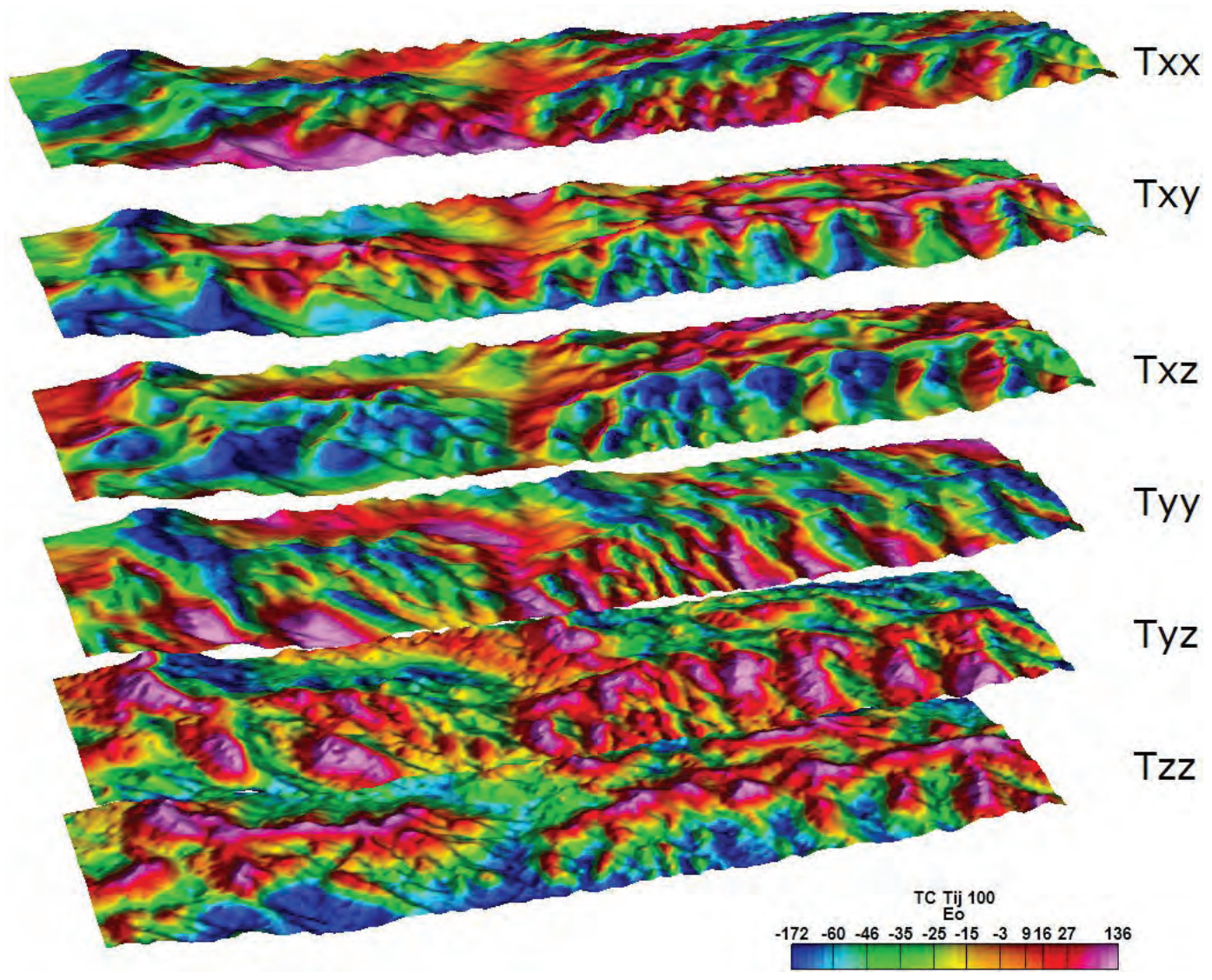

Figura 2 - Respostas das componentes do tensor de aerogradiometria gravimétrica, calculadas a partir do modelo digital de terreno da região do Baú-Gandarela. 


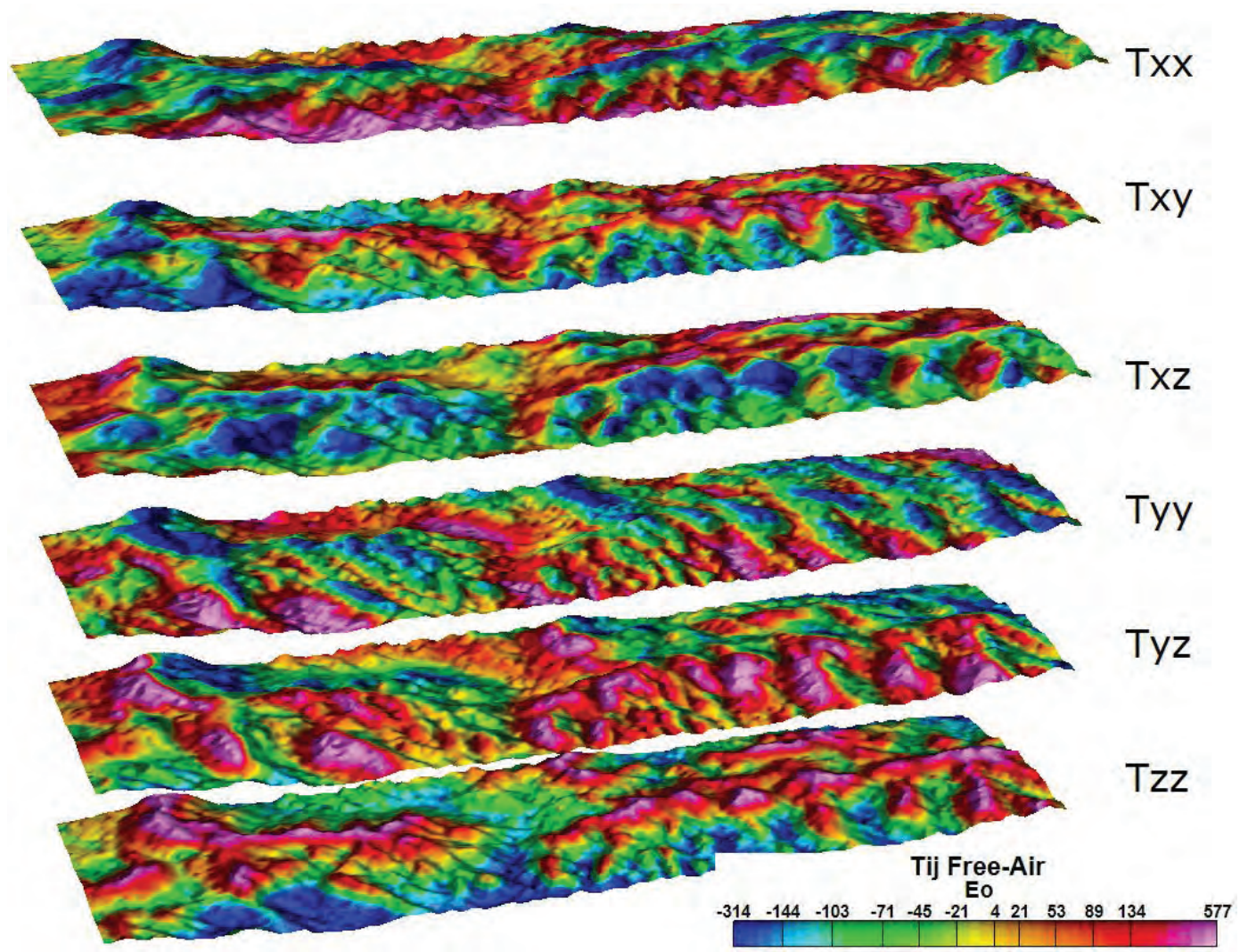

Figura 3 - Dados de Free-Air das componentes do tensor de aerogradiometria gravimétrica, medidos durante a aquisição de dados na região do Baú-Gandarela.

\section{Modelo Digital de Terreno}

0 modelo digital de terreno (MDT) é uma representação aproximada da superfície do terreno, constituído de pontos devidamente espaçados, formando uma malha regular ou irregular de pontos, com coordenadas espaciais.

\section{Modelo Digital de Terreno do SRTM}

0 MDT SRTM coletado pela Nasa (Fig. 5(A)) utilizado neste estudo tem resolução de 90 metros. A resolução é a distância entre os pontos que formam a "nuvem de pontos" do MDT. Os produtos cartográficos derivados dos dados do SRTM foram originalmente amostrados de uma malha regular de 1 arco de segundo por 1 arco de segundo (aproximadamente $30 \mathrm{~m} \times 30 \mathrm{~m}$ ), (Farr et al., 2007), ou seja, a distância aproximada entre os pontos que formam o MDT do SRTM é de 30 metros.

Entretanto, foi estabelecido um acordo entre a Nasa e a Nima (National Imagery and Mapping Agency) que os produtos com resolução de 30 metros estariam disponíveis apenas para os EUA e para o mundo todo ficou disponibilizado uma amostragem de 3 arcos de segundo por 3 arcos de segundo (aproxima- damente $90 \mathrm{~m} \times 90 \mathrm{~m}$ ) reamostrados dos dados originais. Os dados distribuídos pelo Serviço Geológico dos Estados Unidos (USGS) foram gerados a partir da média dos valores originais, em uma janela de $3 \times 3$ pixels, resultando num modelo suavizado em relação ao original. Os dados disponibilizados pela Nasa foram gerados a partir do valor do pixel central da janela de $3 \times 3 \mathrm{e}$, portanto, possuem informações dos dados originais (Grohmann et al., 2008).

Para o processamento de dados de gradiometria gravimétrica o mais importante é a acurácia na componente vertical, porque o MDT é utilizado para avaliar altitudes e não para marcar planimetria. A questão é que o erro planimétrico "produz" um erro altimétrico, que é nulo se o terreno for plano, mas que pode ser muito significativo se 0 terreno for escarpado.

A acurácia reporta, a rigor, a diferença entre a posição exata que o ponto do MDT deveria ter e a posição real que ele tem, como resultado da medição pelo laser ou pelo radar SRTM. 0 SRTM tem uma exatidão estimada menor que 16 metros, para a resolução de 30 metros (Farr et al., 2007). Para a resolução de 90 metros, a precisão vertical estimada é de 16 metros (Pinheiro, 2006). 


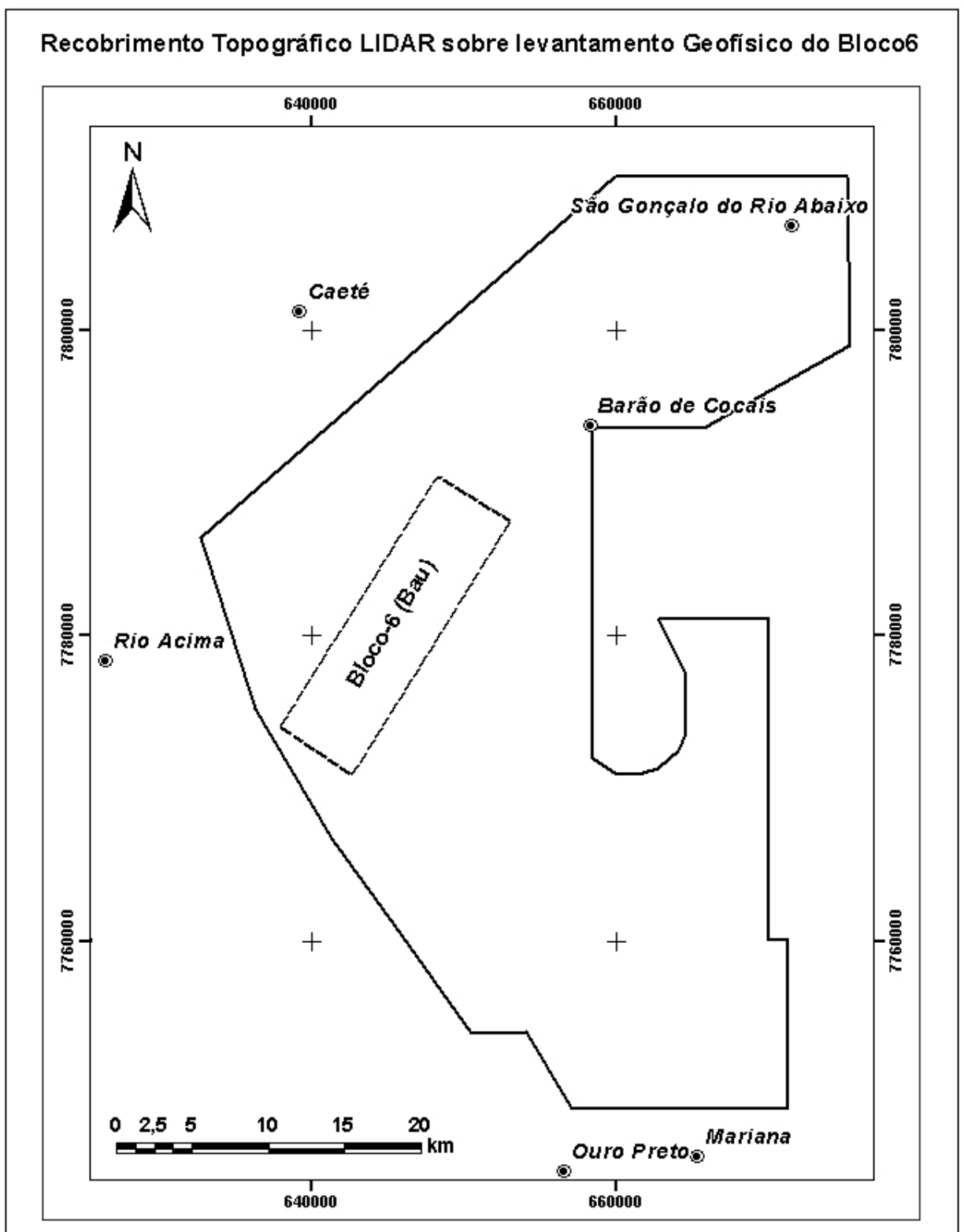

Figura 4 - Localização dos limites do levantamento topográfico a laser (polígono) e do levantamento de aerogradiometria gravimétrica 3D-FTG (retângulo).

\section{Modelo Digital de Terreno a Laser}

0 MDT a laser (Fig. 5(B)) tem resolução de 1 metro e foi classificado como PEC (Padrão de Exatidão Cartográfica), Classe A. 0 decreto $n^{\circ} 89.817$ de 20 de junho de 1984, estabeleceu critérios para a classificação de Carta quanto à exatidão, obedecendo ao Padrão de Exatidão Cartográfica. No capítulo II, sessão 2, artigo $9^{\circ}$ do referido decreto, ficou definido que: "Classe A - Padrão de Exatidão Cartográfica - Altimétrico: metade da equidistância entre as curvas de nível, sendo de um terço desta equidistância 0 erro-padrão correspondente. Além disso, o decreto determina que noventa por cento dos pontos isolados de altitude não deverão apresentar erro superior ao PEC - Altimétrico estabelecido.

0 MDT a laser da região do estudo tem uma resolução média de 1 ponto a cada 1,5 $\mathrm{m}^{2}$. Isso é devido a uma distância entre pontos do MDT, de pouco mais de 1 metro, ou seja, o laser desta região tem cerca de 90 vezes mais resolução (mais pontos) do que o SRTM. Esses números são todos estimativos, 
(A)

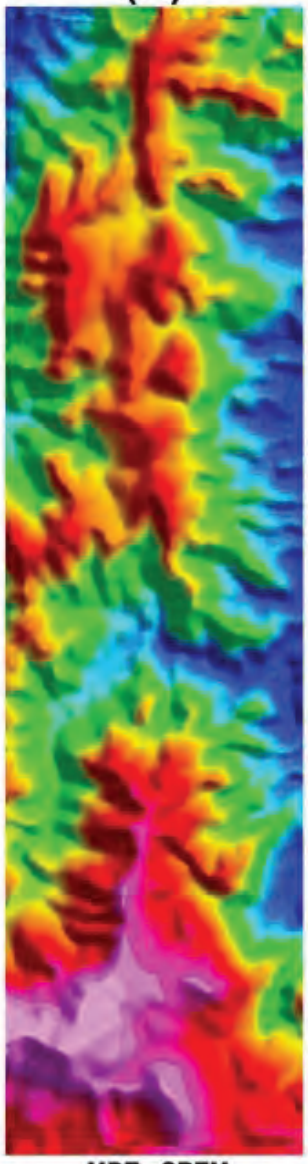

MDT - SRTM

metros

$78292199010411098114912011281 \quad 1646$

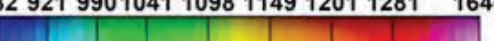

(B)

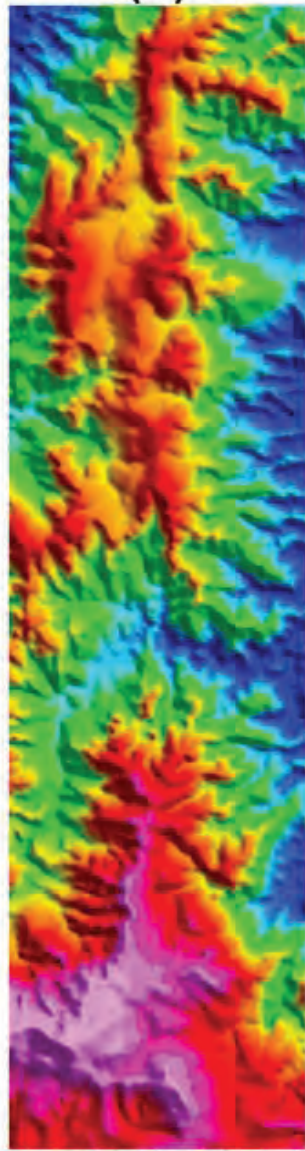

MDT - LASER

metros

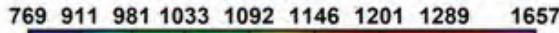

Figura 5 - (A) Modelo digital de terreno do SRTM (Shuttle Radar Topography Mission) da região do Baú-Gandarela, coletado pela Nasa com acurácia de 90 metros. (B) Modelo digital de terreno a laser da região do Baú-Gandarela, coletado pela Vale com acurácia de 1,6 metros.

porque dependem sempre das circunstâncias do terreno. Numa área sem vegetação (Fig. 6) a resolução aumenta muito, porque todos os pontos medidos pelo laser estão "no chão". Numa área com densa cobertura arbórea, muitos pontos ficam pelas copas das árvores, e no limite, pode ser que nenhum ponto atinja o chão. A Figura 7 mostra de forma esquemática os retornos dos pulsos laser durante 0 perfilamento onde os pontos que atingem 0 terreno serão os formadores do MDT.

A acurácia vertical final destes dados, já considerando a participação dos erros horizontais, foi de 1,6 metros.

As avaliações foram feitas para que o MDT a laser se enquadrasse apenas na classificação A, assim para os cálculos foi usada a escala de 1:5.000.

Verificou-se através dos critérios estabelecidos pelo PEC, que para a elaboração de cartas Classe A na escala 1:5.000 o erro máximo permitido na vertical seria de 2,50 metros, o que trouxe uma exatidão maior ao processamento dos dados de gradiente de gravidade utilizando o MDT a laser.

\section{Qualidade resultante das diferenças entre o MDT SRTM e o MDT Laser}

Para este estudo foi calculada a diferença (Fig. 8) entre o modelo digital de terreno do SRTM (Fig. 5(A)) e o modelo digital de terreno a laser (Fig. 5(B)) na área do levantamento geofísico 3D-FTG. As diferenças na altimetria entre os dois modelos e suas influências nas correções de terreno dos dados de gradiometria gravimétrica serão abordadas mais a frente nesta seção. 

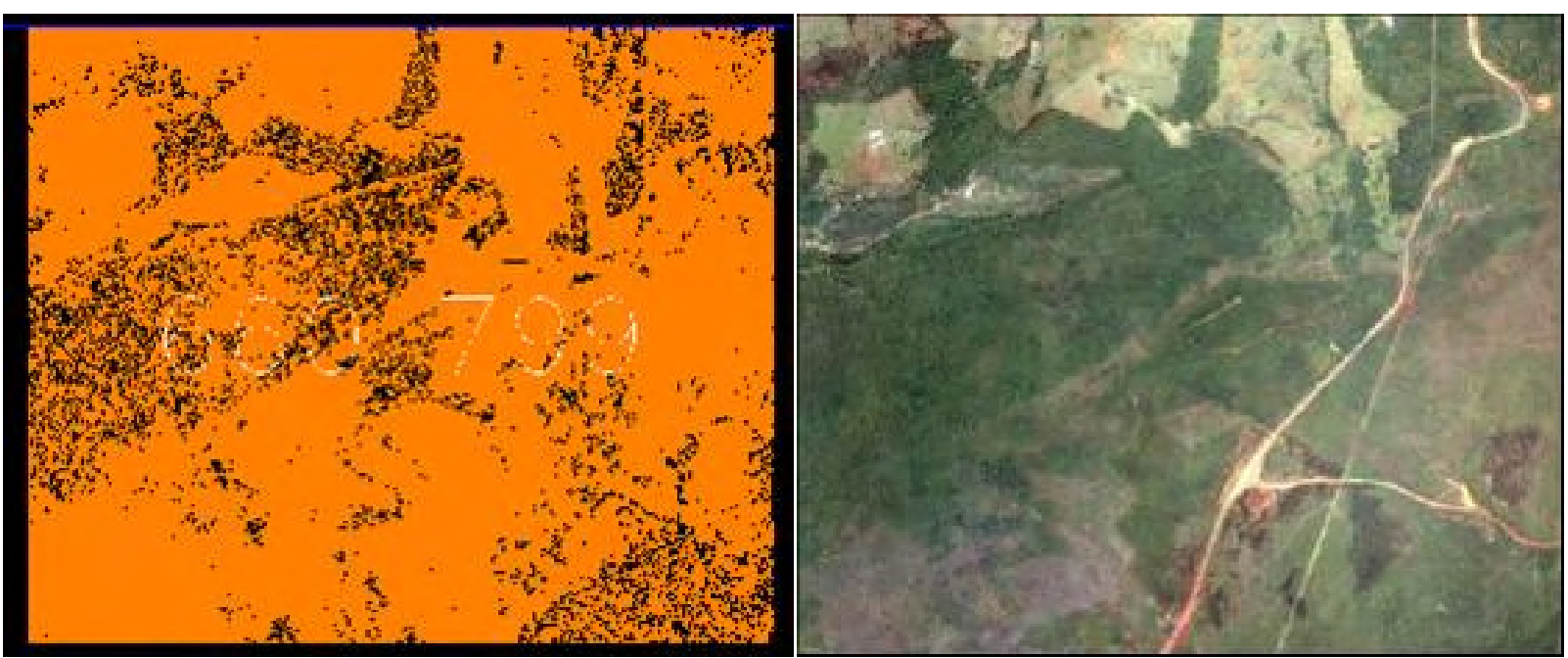

Figura 6 - Modelo digital de terreno a laser da folha articulada 660-799. № lado esquerdo da figura, os pontos do MDT e do lado direito a imagem da ortofoto correspondente. Nas áreas completamente preenchidas pela cor sépia, o terreno encontra-se descoberto. Nas regiões pontilhadas percebe-se pela ortofoto, que são áreas de vegetação.

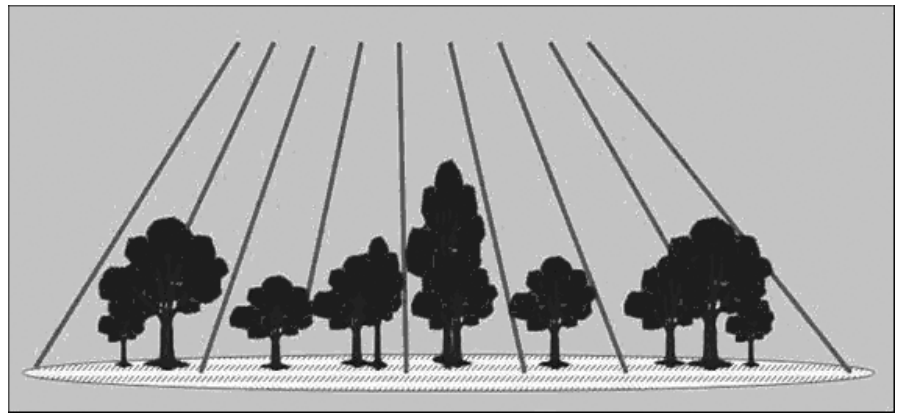

Figura 7 - Geração do modelo digital de terreno.

A acurácia do MDT não pode ser estimada somente pelas questões instrumentais, ou seja, pelo processo de medição (laser ou radar). As características da área que é varrida de pontos pelo sensor influenciam muito na qualidade do processo de medição, tanto para o radar quanto para o laser.

Em áreas com terreno muito movimentado e com declividades acentuadas, a resolução influencia muito. Com um ponto afastado do outro, em cerca de 1 metro, podemos caracterizar muito melhor a modelagem do terreno do que com pontos a cada 90 metros. Entre cada ponto, no SRTM, existe muita variação de terreno em 90 metros, e só é possível caracterizar as macro feições do terreno, ou seja, as grandes estruturas. Em certos casos, com certeza, a acurácia será pior do que os 16 metros estimados.

Em áreas com densa cobertura vegetal, o terreno fica "invisível" de cima. Os dois métodos ativos têm penetrabilidade na vegetação, mas a eficiência desta penetrabilidade varia muito em função das circunstâncias, inclusive em função do tipo de cobertura vegetal. No caso dos dados de laser aqui mostrados, numa área limpa, a acurácia chega aos 0,4 ou 0,5 metros. Já nas áreas com densa cobertura vegetal, considera-se que a exatidão fique em torno de 1,6 metros. Quanto ao MDT SRTM, nas áreas limpas estima-se algo em torno dos 6 metros de acurácia enquanto que nas áreas florestadas esta gira em torno de 10 a 15 metros.

A comparação entre o MDT SRTM e o MDT laser é muito subjetiva, porque tanto a resolução quanto a acurácia são fatores muito circunstanciais.

0 resultado desta comparação mostra que a diferença na altimetria entre os dois modelos pode variar de -68 metros até +69 metros, ou seja em pelo menos 1 ponto a cota do MDT SRTM está 68 metros abaixo da cota do MDT a laser e que pelo menos 1 ponto a cota do MDT SRTM está 69 metros acima da cota do modelo digital de terreno a laser. A Figura 8 mostra que 
as maiores diferenças entre os dois modelos (cores magenta $\mathrm{e}$ azul) estão nas encostas, vales e topos da região. As regiões com topografia mais suave são representadas pelas cores verde e amarela.

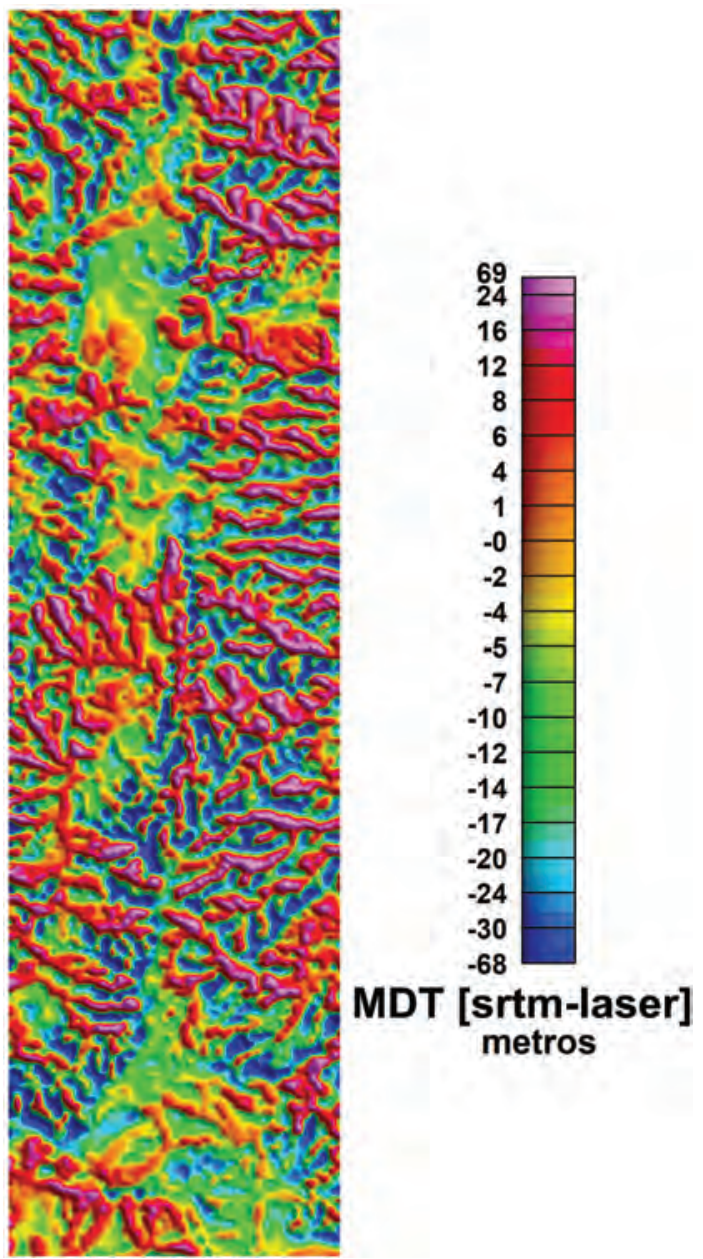

Figura 8 - Mapa da diferença entre o modelo digital de terreno do SRTM e a laser da região do Baú-Gandarela, mostrando que as maiores diferenças entre os dois modelos (cores magenta e azul) estão nas encostas, vales e topos da região de estudo. As regiões com topografia mais suave são representadas pelas cores verde e amarela.

Como o modelo digital de terreno do SRTM tem uma resolução de 90 metros e a interpolação tende a suavizar o MDT, os altos topográficos tendem a estar suavizados e os vales tendem a estar mais altos do que a realidade. 0 modelo digital de terreno a laser por apresentar uma resolução de 1 metro, ressalta os detalhes da área com maior precisão.

Agora que conhecemos as diferenças entre os modelos digitais de terreno da área em questão, temos como próximo passo realizar a correção de terreno nos dados de aerogradiometria gravimétrica 3D-FTG. Assim poderemos observar, quais efeitos que topografias com precisão distintas causam no resultado final do levantamento geofísico.

\section{Aplicação da correção de terreno \\ Gradiente da gravidade sintético, calculado do modelo digital de terreno a laser}

0 modelo digital de terreno a laser da região do Baú-Gandarela foi utilizado para calcular as componentes do tensor do gradiente da gravidade devido à topografia, de forma que 0 gradiente da gravidade gerado (Fig. 9), possa ser subtraído dos gradientes da gravidade medidos durante a aquisição de dados na área do aerolevantamento geofísico de 3D-FTG (Fig. 10). 0 cálculo das componentes calculadas foi desenvolvido com a elaboração de um algoritmo computacional utilizando-se as Equações (2) a (7).

\section{Preparação dos dados de Free-Air}

As componentes do tensor dos dados de Free-Air, $T_{x x} F A$, $T_{x y-} F A, T_{x z-} F A, T_{y y-} F A, T_{y z-} F A$ e $T_{z z-} F A$ foram interpoladas usando o método de mínima curvatura (Briggs, 1974). Cada componente do tensor responde por aspectos diferentes da geologia (Fig. 10).

As componentes $T_{x x}$ e $T_{y y}$ identificam, respectivamente, as variações de características geológicas norte-sul, leste-oeste e também determina os limites leste-oeste e extremidades nortesul dos corpos. A componente $T_{x y}$ identifica características estruturais nordeste-sudoeste e noroeste-sudeste dos corpos. $T_{x z}$ e $T_{y z}$ identificam os centros de massa dos corpos na direção norte-sul e leste-oeste, podendo, também, identificar falhas e diques. A componente $T_{z z}$ reflete diretamente a geologia da subsuperfície. Essa componente determina diretamente onde estão os alvos para pesquisa e exploração e tem mapeado com precisão tanto a formação ferrífera quanto as hematitas.

\section{Análise de correção de densidade}

A escolha da densidade ótima para correção da influência do terreno é crítica para separar os sinais obtidos da geologia, dos sinais relacionados à topografia.

0 cálculo assume prismas 3D com uma densidade de $1,0 \mathrm{~g} / \mathrm{cm}^{3}$ e calcula a resposta de gravidade de um modelo que representa a massa de terra entre 0 terreno e 0 elipsóide. Isto produz as componentes do tensor que contêm principalmente os efeitos gravitacionais da geologia acima do nível de referência (nível do mar). Esta correção pode ser facilmente usada para 

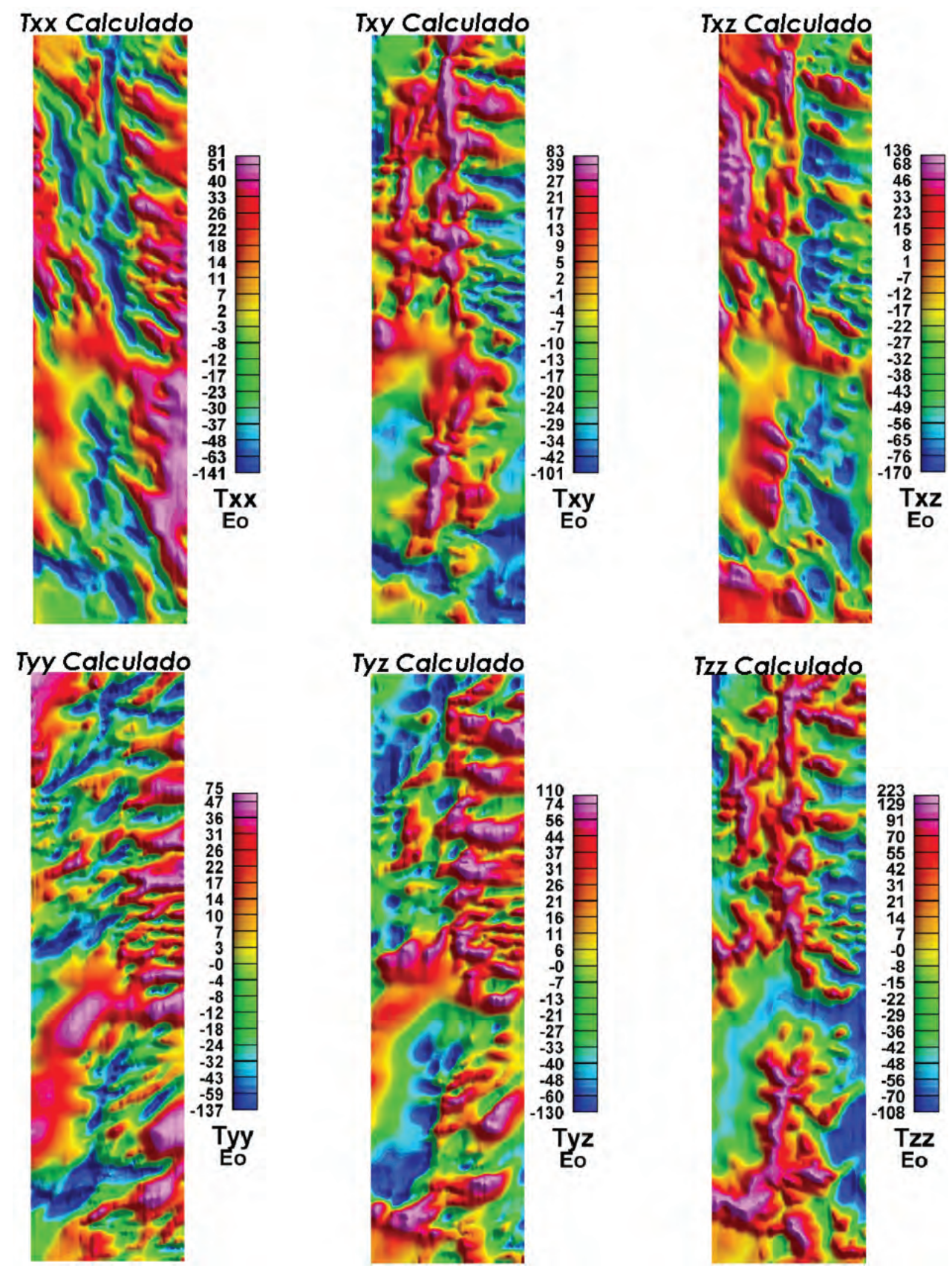

Figura 9 - Mapas das componentes calculadas do tensor de gradiometria gravimétrica, com base no modelo digital de terreno a laser da região do Baú-Gandarela.

qualquer valor de densidade e pode ser calculada por:

$$
a=b-\rho \cdot c
$$

onde:

$a$ = componente $T_{z z}$ corrigida da influência da topografia para um MDT a laser para uma densidade de $2,7 \mathrm{~g} / \mathrm{cm}^{3}$ $\left(T_{z z-} T C_{-} 267\right)$ $b=$ componente $T_{z z}$ Free-Air $\left(T_{z z-} F A\right)$

$c=$ correção de terreno a laser para a componente $T_{z z}$ para uma densidade de $1,0 \mathrm{~g} / \mathrm{cm}^{3}\left(T_{z z}\right.$ sintético_100) $\rho=\operatorname{densidade}\left(\mathrm{g} / \mathrm{cm}^{3}\right)$.

Considerando as dimensões da área de pesquisa, um único valor de densidade não deve ser usado para uma exploração de caráter regional. Para a prospecção de um depósito ou até 

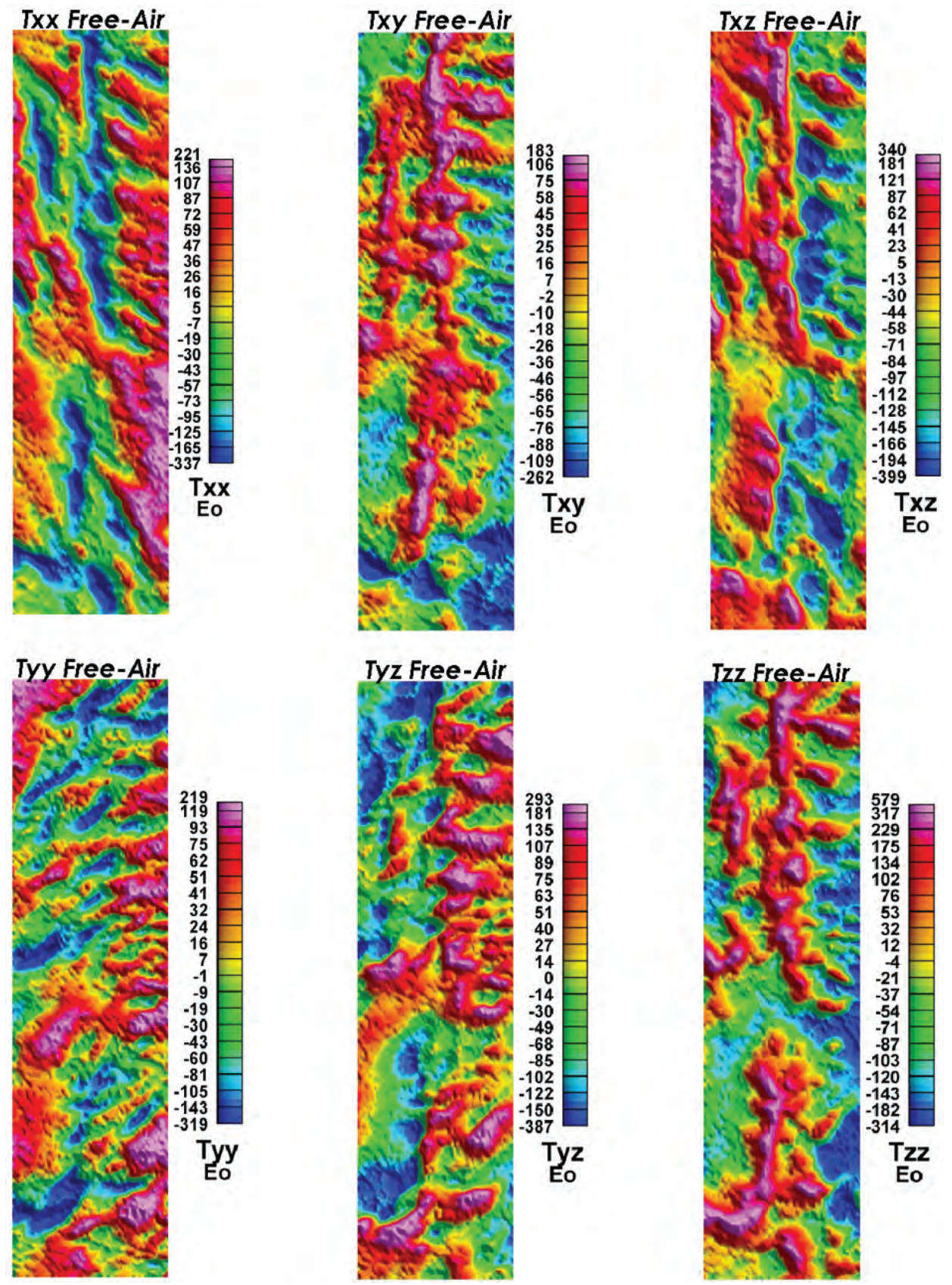

Figura 10 - Mapas Free-Air das componentes do tensor de gradiometria gravimétrica da região do Baú-Gandarela, cada um mostrando os diferentes atributos da geologia local.

mesmo a nível regional é importante usar densidades variadas nas correções de terreno, pois as densidades em subsuperfície são distintas. 0 uso de densidades variadas ajudará na interpretação geológica desses dados geofísicos. Para evidenciar a importância da correção de terreno, densidades que variam de $1,5 \mathrm{~g} / \mathrm{cm}^{3}$ a $4,5 \mathrm{~g} / \mathrm{cm}^{3}$ foram utilizadas para determinar 0 me-
Ihor valor de densidade que minimiza o efeito de terreno dos dados de Free-Air medidos. A seguir apresentaremos esses resultados para a componente $T_{z z}$ corrigidas com o MDT a laser e SRTM, pois essa componente é a que melhor expressa a geologia local.

Com o objetivo de mostrar a geologia e definir o grau de in- 
(a) Mapa geológico

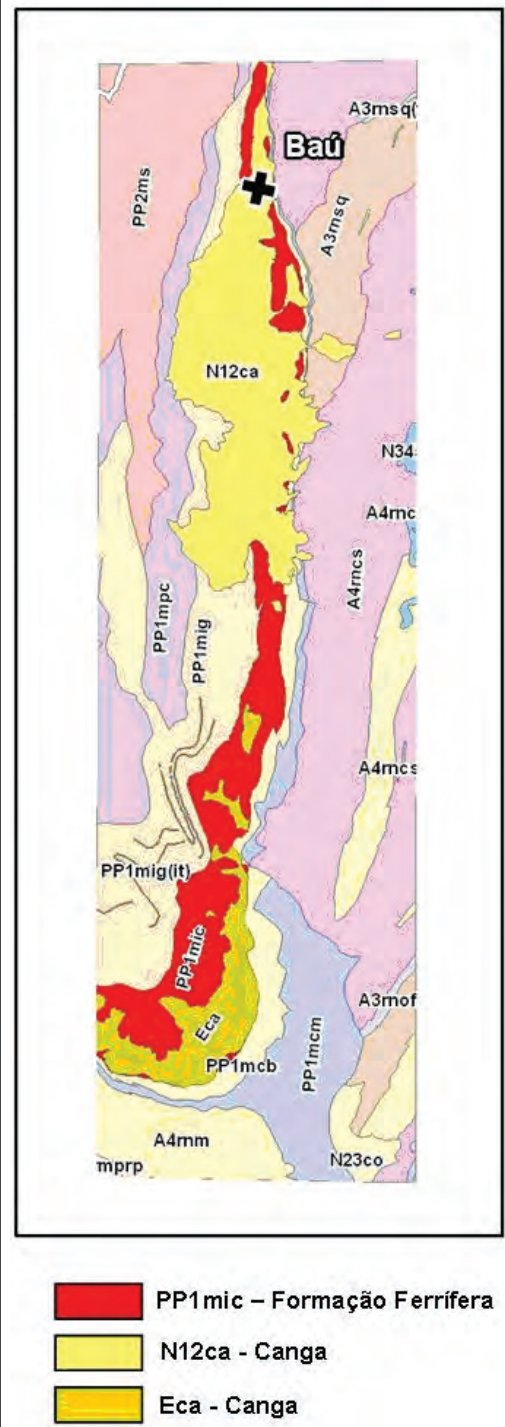

(b) MDT laser
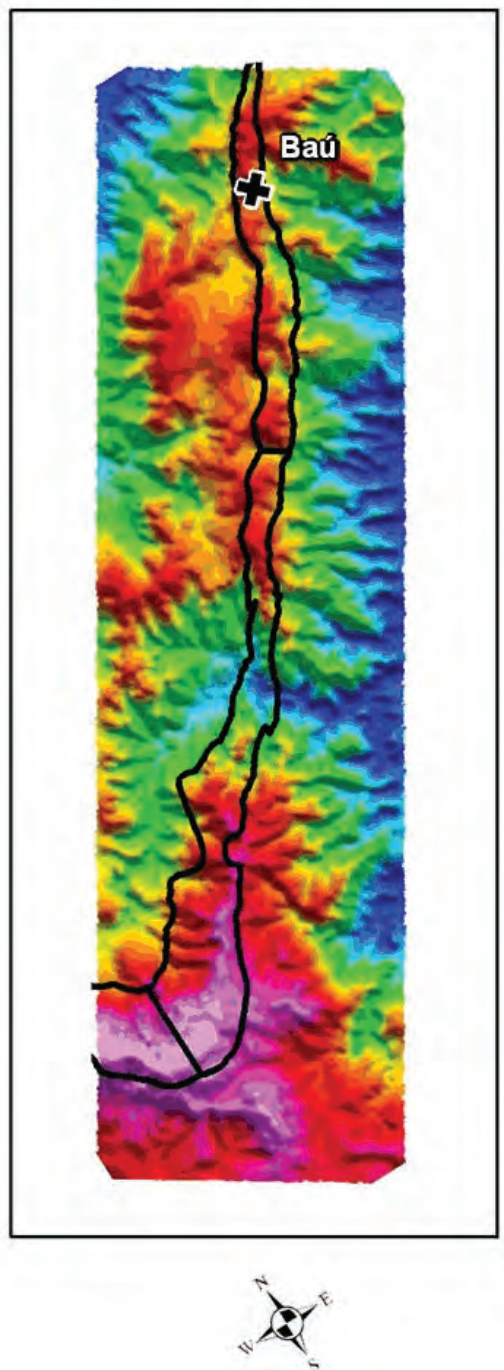

$1: 150.000$ (c) Tzz_TC_laser_1.5

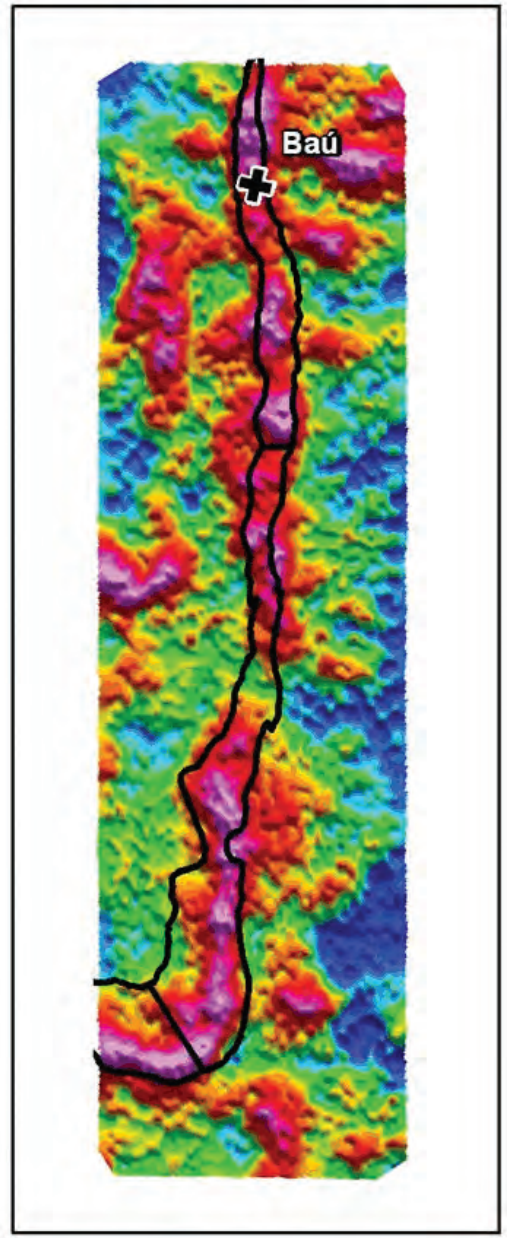

1. Mina do Baú

B Formação Ferrifera $00,51 \quad 2 \quad 3 \quad 4 \quad 5 \quad k m$

Figura 11 - Mapa geológico (a) do Baú-Gandarela (Dorr, 1969), modelo digital de terreno a laser (b) e componente $T_{z z}$ corrigida com o MDT a laser (c). A linha preta é o limite da formação ferrífera.

fluência do terreno (topografia) no dado final da componente $T_{z z}$ na Figura 11 é apresenta o mapa geológico (a), o modelo digital de terreno a laser (b) e a componente $T_{z z}$ corrigida $\operatorname{com} \rho=$ $1,5 \mathrm{~g} / \mathrm{cm}^{3}$ o MDT a laser (c) da região do Baú-Gandarela.

A Figura 12 apresenta o resultado da componente $T_{z z}$ corrigida com a densidade de $1,5 \mathrm{~g} / \mathrm{cm}^{3}$ e $2,0 \mathrm{~g} / \mathrm{cm}^{3}$. Para a densidade de 2,0 $\mathrm{g} / \mathrm{cm}^{3}$, os dados corrigidos com 0 MDT do SRTM continuam apresentando alta correlação com a topografia, a formação ferrífera não apresenta continuidade, já a correção feita com o MDT do laser é possível perceber a continuidade da formação ferrífera mapeada na região, mas os efeitos da topografia ainda são visíveis.

Na Figura 13, é possível perceber que para densidade 2,7 g/ $/ \mathrm{cm}^{3}$ os dados corrigidos com o MDT do SRTM apresentam falsas anomalias para prospecção de hematita e os alvos verdadeiros não estão presentes, pois esses alvos foram validados com base em geologia de campo e furos de sondagem. $\mathrm{Na}$ correção feita com o MDT a laser é possível perceber os corpos e os alvos de hematita existentes na região do Baú-Gandarela com extrema precisão. Quando aumentamos a densidade para 


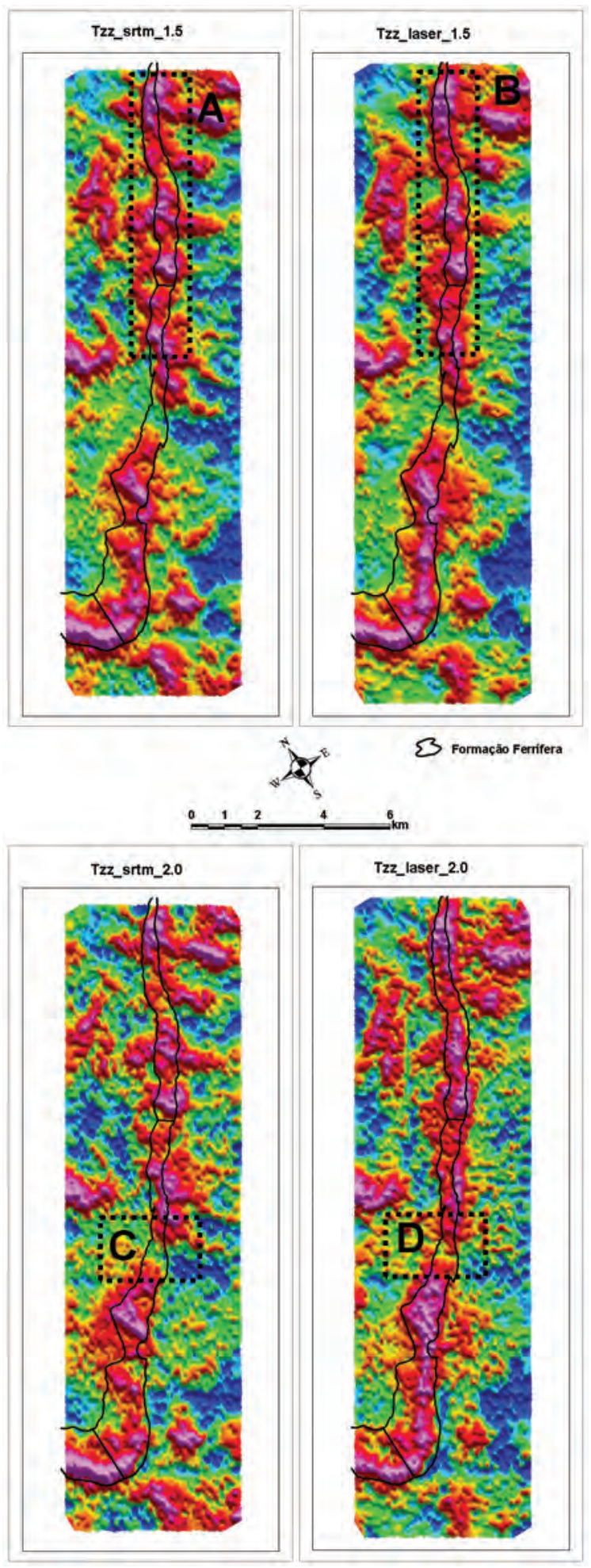

Figura 12 - Componente $T_{z z}$ corrigida com o MDT do SRTM e laser para densidade de 1,5 e 2,0 $\mathrm{g} / \mathrm{cm}^{3}$. É possível perceber 0 efeito da topografia da região para ambas as densidades, porém, os dados corrigidos com o MDT a laser e densidade $2,0 \mathrm{~g} / \mathrm{cm}^{3}$ possui mais detalhes e delimita a formação ferífera da área (polígono de cor preta). (A) Efeitos causados pelo MDT impreciso do SRTM e por uma densidade baixa. (B) Efeitos causados basicamente pelo uso de uma densidade baixa. (C) Devido à imprecisão do SRTM a continuidade da formação ferrífera não é percebida. (D) Com o aumento do valor da densidade é possível perceber a continuidade da formação ferrífera. 

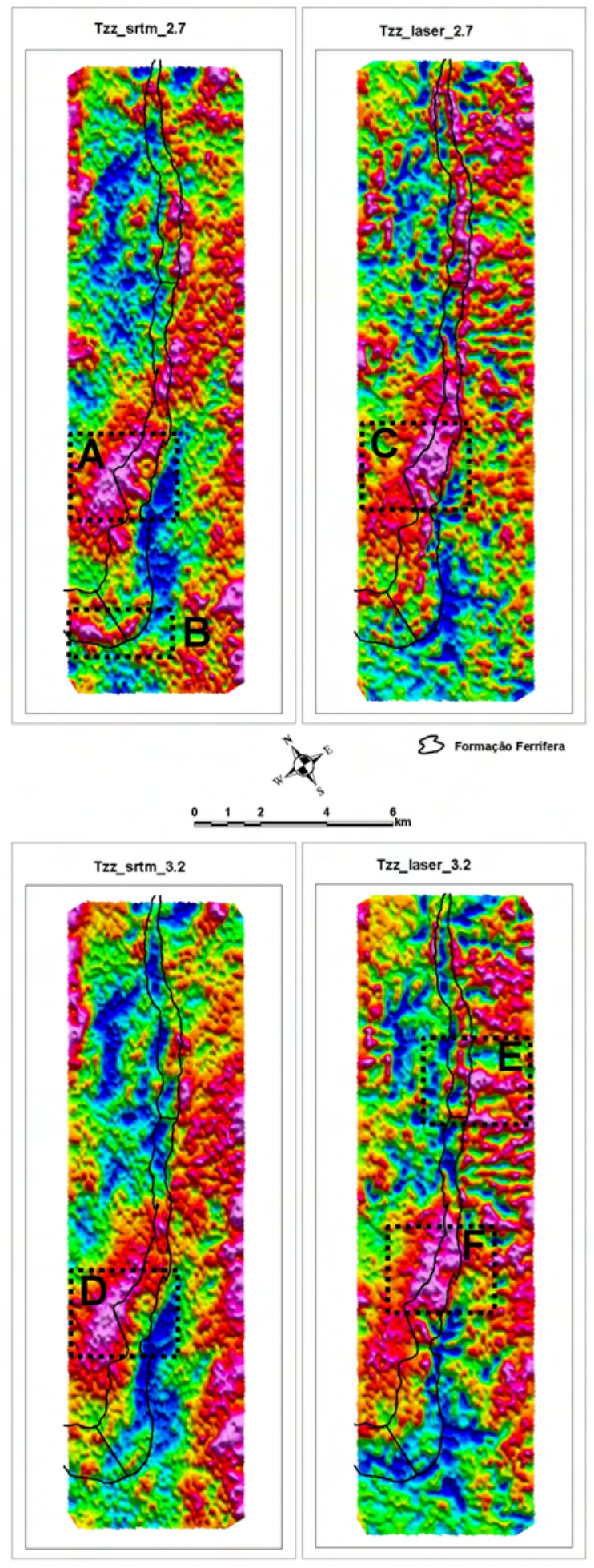

Figura 13 - Componente $T_{z z}$ corrigida com o MDT do SRTM e laser para as densidades de 2,7 e 3,2 $\mathrm{g} / \mathrm{cm}^{3}$. (A) e (B) falsos alvos para prospecção de hematita foram criados, são efeitos basicamente causados pela resolução do MDT. Os alvos verdadeiros não apareceram. (C) Com a correção da densidade para $2,7 \mathrm{~g} / \mathrm{cm}^{3}$, os corpos e alvos de hematita da região podem ser percebidos. (D) Para a densidade $3,2 \mathrm{~g} / \mathrm{cm}^{3} \mathrm{a}$ formação ferrífera praticamente desapareceu e mais um alvo falso foi criado. (E) Sinais de overcorrection já são percebidos em toda borda leste e nordeste do mapa. (F) Para a densidade $3,2 \mathrm{~g} / \mathrm{cm}^{3}$, os corpos e alvos de hematita da região podem ser percebidos, mas são mais restritos. 
3,2 $\mathrm{g} / \mathrm{cm}^{3}$ os dados corrigidos com o MDT do SRTM a formação ferrífera mapeada na região praticamente desapareceu e alvos falsos para a prospecção de ferro foram criados, informações essas validadas com geologia de campo e sondagem. Na correção feita com o MDT a laser os corpos e os alvos de hematita existentes na região continuam presentes, porém artefatos (overcorrections) foram criados na região das rochas encaixantes, devido à alta densidade usada na correção.

Na Figura 14, é possível perceber que para as densidades 3,7 e $4,2 \mathrm{~g} / \mathrm{cm}^{3}$ nos dados corrigidos com 0 MDT do SRTM a formação ferrífera não está mais presente. Na correção feita com 0 MDT a laser 0 alvo principal para a prospecção de hematita permanece, porém os sinais de overcorrection estão bem mais fortes nas rochas encaixantes. A conclusão que chegamos é que o melhor mapa a ser utilizado é 0 corrigido com o MDT a laser e densidade $2,7 \mathrm{~g} / \mathrm{cm}^{3}$ (dentre as densidades de 1,5 a $4,5 \mathrm{~g} / \mathrm{cm}^{3}$ ), pois este define bem a formação ferrífera, os efeitos da topografia foram removidos e os alvos para a prospecção de hematita ficaram mais evidenciados.

Como 0 valor de $2,7 \mathrm{~g} / \mathrm{cm}^{3}$ foi escolhido como densidade ótima a ser usada na correção da influência topográfica e seus resultados (Fig. 15) serão usados na interpretação geológica dos dados geofísicos. Para efeito de comparação e interpretação geológica, os dados de aerogradiometria gravimétrica também foram corrigidos do terreno com o modelo digital de terreno gerado a partir da topografia do SRTM e densidade $2,7 \mathrm{~g} / \mathrm{cm}^{3}$ (Fig. 16).

\section{Comparação entre os resultados da correção de terreno com SRTM e Laser}

Nesta etapa foi realizada uma comparação entre os dados de aerogradiometria gravimétrica corrigidos do terreno com modelo digital de terreno gerado pela topografia a laser e os dados de aerogradiometria gravimétrica corrigidos do terreno com modelo digital de terreno gerado pelo SRTM.

Visto que a componente do tensor de aerogradiometria gravimétrica reflete diretamente a geologia da subsuperfície e estabelece onde estão os alvos para pesquisa e exploração é a componente $T_{z z}$, a mesma será usada neste estudo comparativo.

A análise da componente $T_{z z}$ é importante, pois é a partir dela que a exploração e pesquisa da área são baseadas. Acreditamos que as diferenças entre os dois modelos digitais de terreno (SRTM e laser) geraram grandes diferenças nas componentes do tensor, especialmente na componente $T_{z z}$ influenciando diretamente na interpretação geológica. Acreditamos que as componentes do tensor corrigidas com o modelo digital a laser refletiram a geologia da região com mais rigor, visto que o modelo digital de terreno a laser se mostrou pelos estudos feitos anteriormente mais preciso do que o modelo digital de terreno do SRTM da Nasa.

0 mapa da Figura 17(A) mostra a componente $T_{z z}$ do tensor de aerogradiometria gravimétrica corrigida com modelo digital de terreno do SRTM e densidade $2,7 \mathrm{~g} / \mathrm{cm}^{3}$.

0 mapa da Figura 17(B) mostra a componente $T_{z z}$ do tensor de aerogradiometria gravimétrica corrigida com modelo digital de terreno a laser e densidade $2,7 \mathrm{~g} / \mathrm{cm}^{3}$. A diferença é facilmente notada, pois os sinais de alta frequência (fontes rasas) aumentaram em relação ao mapa corrigido com SRTM (Fig. 17(A)).

0 mapa da Figura 18 mostra a diferença entre a componente $T_{z z}$ do tensor de aerogradiometria gravimétrica corrigida do terreno com modelo digital de terreno do SRTM e a componente $T_{z z}$ do tensor corrigida do terreno com modelo digital de terreno a laser.

As medidas dos gradientes de gravidade coletadas durante a aquisição desses dados, trabalham em função da variação lateral de densidade das rochas distribuídas na superfície e subsuperfície e da distância entre os corpos geológicos e o sistema de aquisição de dados. Esses valores podem sofrer alterações se o modelo digital de terreno utilizado para a correção de terreno for impreciso.

De fato, os dados de aerogradiometria gravimétrica, corrigidos com o modelo digital de terreno do SRTM, estão aquém das expectativas e não são confiáveis para o uso na exploração e pesquisa. A imprecisão do modelo digital de terreno do SRTM faz com que a correção de terreno seja imprecisa, ou seja, a componente $T_{z z}$ corrigida do terreno com o modelo digital do SRTM pode remover alvos potenciais verdadeiros e adicionar alvos falsos. Os valores negativos (cor azul), no mapa da Figura 18, representam as regiões onde após a correção de terreno o sinal do gradiente de gravidade foi subestimado, devido a esta correção ser realizada com um modelo digital de terreno impreciso, ou seja, alvos verdadeiros para prospecção podem ter sido removidos. Os valores positivos (cor magenta) representam as regiões onde após a correção de terreno 0 sinal do gravidade de gravidade foi superestimado, falsos alvos para prospecção podem ter sido criados.

0 resultado mostra que a imprecisão do modelo digital do SRTM pode causar desvios gravíssimos no resultado da componente $T_{z z}$ refletindo diretamente na interpretação da geologia da região, na avaliação do potencial mineral da área e nas ações de pesquisa e exploração. 

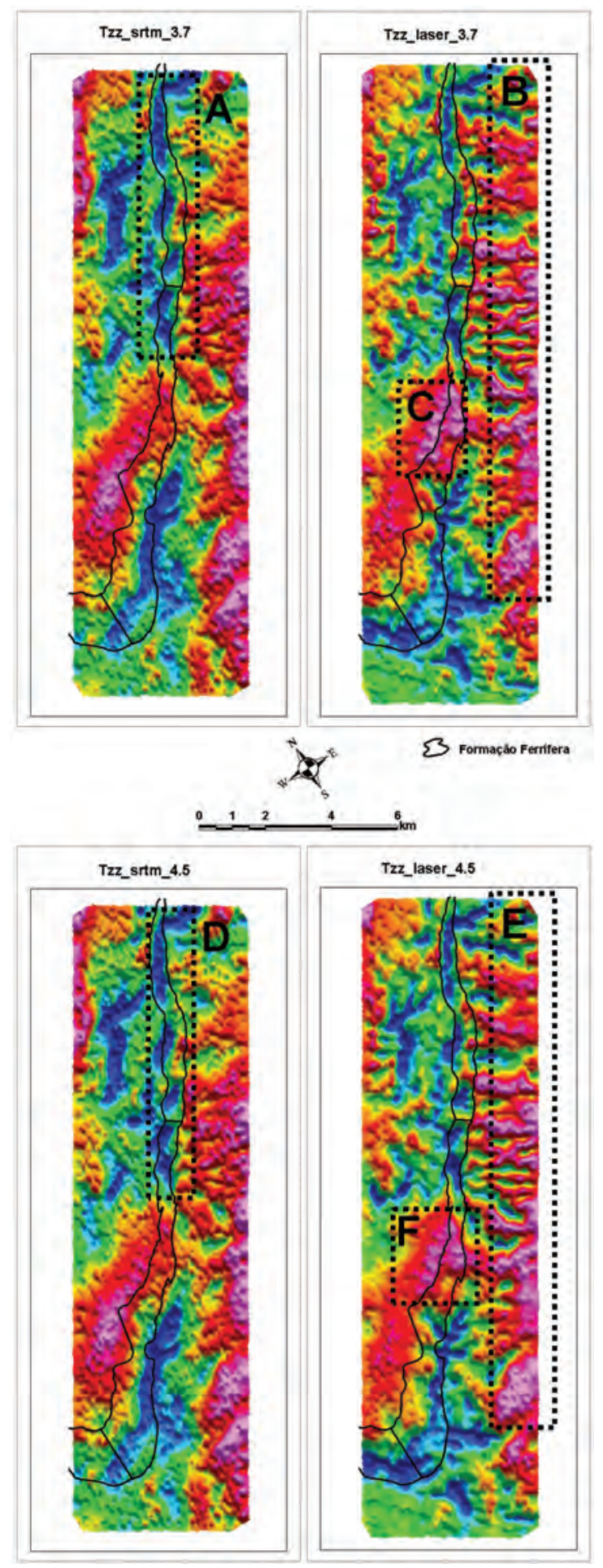

Figura 14 - Componente $T_{z z}$ corrigida com o MDT do SRTM e laser para as densidades de $3,7 \mathrm{e} 4,5 \mathrm{~g} / \mathrm{cm}^{3}$. (A) Para a densidade $3,7 \mathrm{~g} / \mathrm{cm}^{3}$ a formação ferrífera desapareceu e sinais de overcorrection são percebidos. (B) Sinais de overcorrection já são percebidos com clareza em toda borda leste e nordeste do mapa. (C) 0 principal corpo e alvo de hematita da região continua aparecendo para a densidade $3,7 \mathrm{~g} / \mathrm{cm}^{3}$. (D) Para a densidade $4,5 \mathrm{~g} / \mathrm{cm}^{3}$ a formação ferrífera desapareceu e sinais de overcorrection são percebidos. (E) Sinais de overcorrection já são percebidos em toda borda leste e nordeste do mapa. (F) 0 principal corpo e alvo de hematita de região continua aparecendo para a densidade $4,5 \mathrm{~g} / \mathrm{cm}^{3}$. 

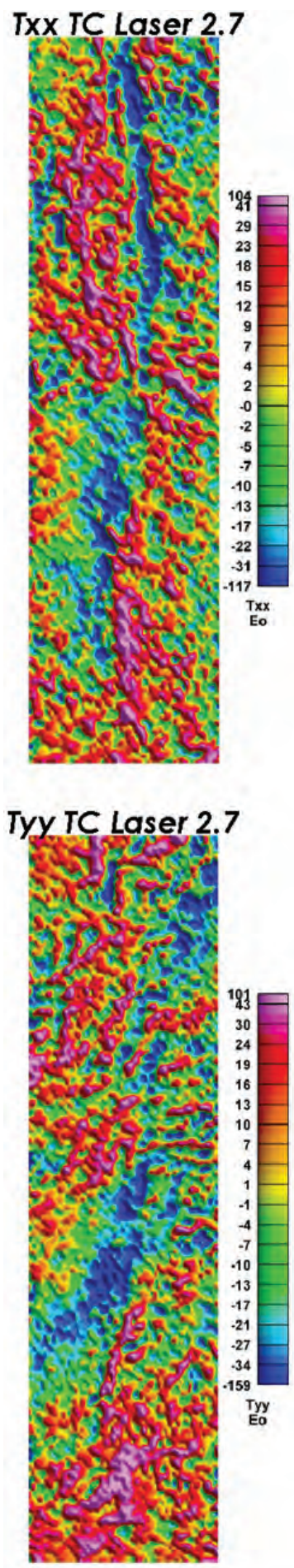

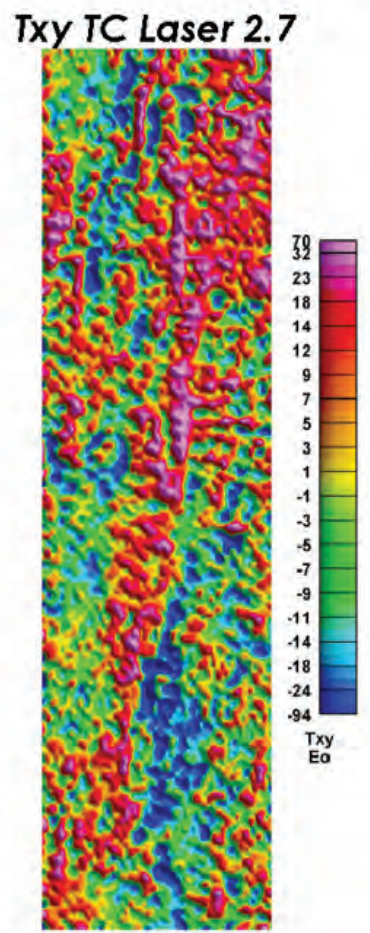

Tyz TC Laser 2.7

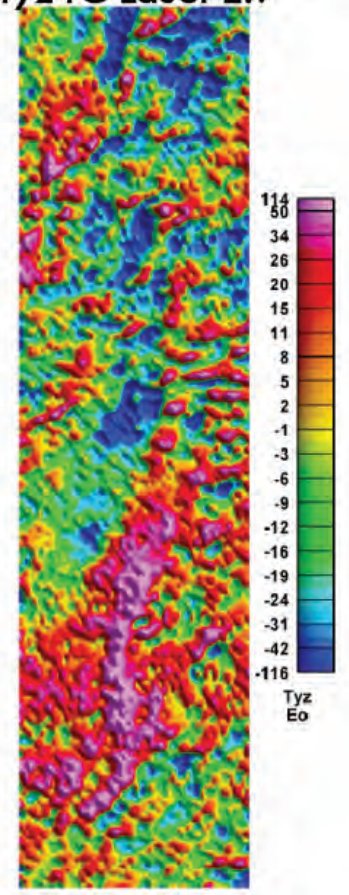

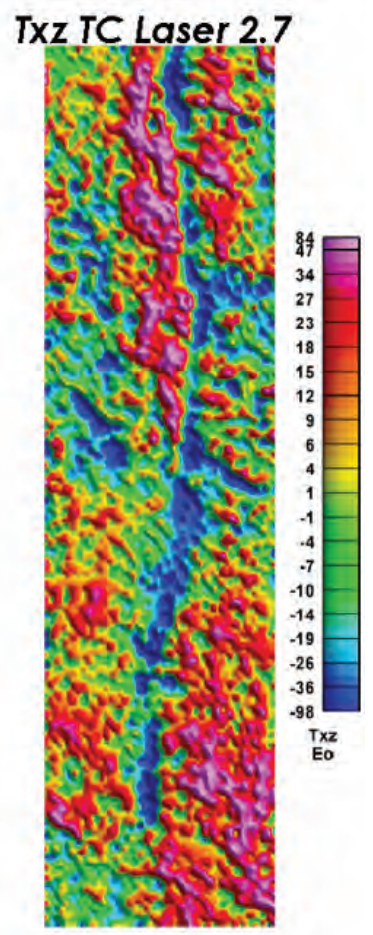

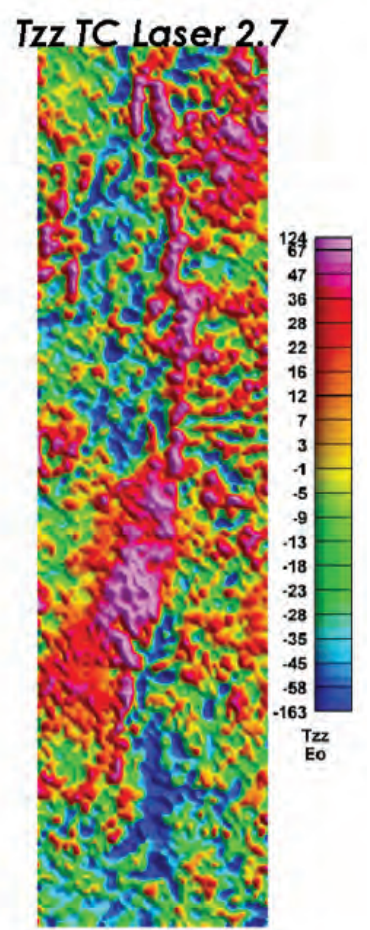

Figura 15 - Mapas das componentes do tensor de gradiometria gravimétrica da região do Baú-Gandarela, corrigidas da influência da topografia usando modelo definido pela topografia a laser para uma densidade de $2,7 \mathrm{~g} / \mathrm{cm}^{3}$, cada componente mostra os diferentes atributos da geologia local. 

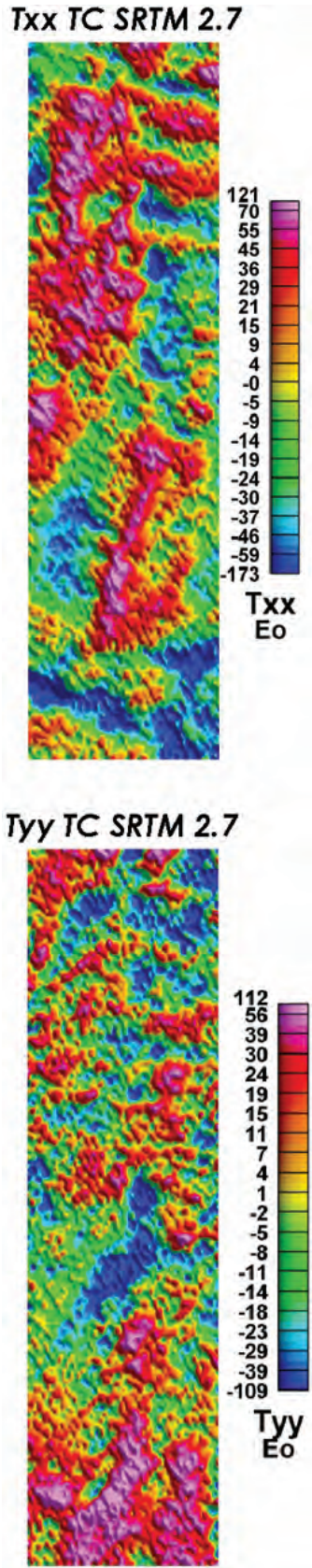

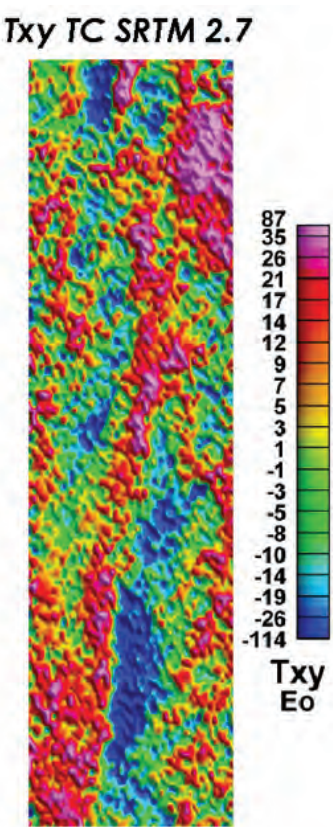

TYZ TC SRTM 2.7

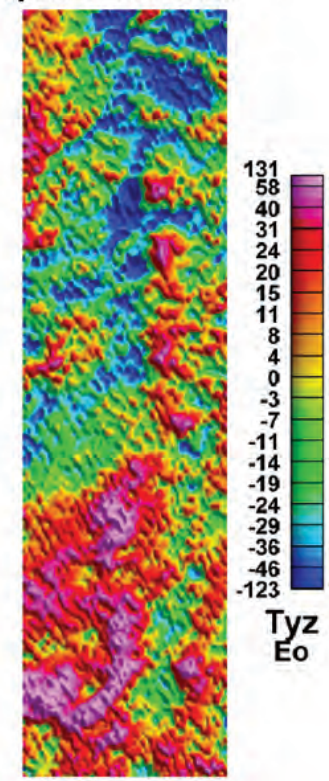

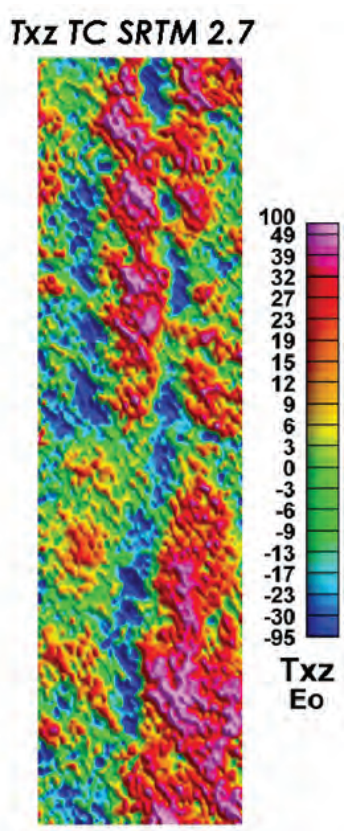

TZZ TC SRTM 2.7

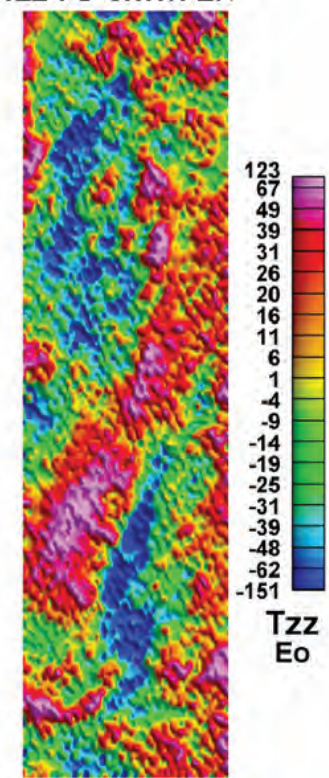

Figura 16 - Mapas das componentes do tensor de gradiometria gravimétrica da região do Baú-Gandarela, corrigidas da influência da topografia usando modelo definido pela topografia do SRTM para uma densidade de $2,7 \mathrm{~g} / \mathrm{cm}^{3}$, cada componente mostra os diferentes atributos da geologia local.

É possível perceber nos resultados apresentados (Fig. 19) grandes mudanças nas feições das anomalias entre a componente $T_{z z}$ corrigida do terreno com o modelo digital de terreno do SRTM e a componente $T_{z z}$ corrigida do terreno com o modelo digital de terreno a laser. Com base nos estudos e conclusões aqui descritos, já se torna possível fazer a interpretação geológica da região.

\section{CONCLUSÃO}

Os cálculos para remoção dos efeitos do terreno requerem um conhecimento a priori detalhado da superfície topográfica local e densidade das rochas na região de cada leitura do gradiente de gravidade. Se a topografia de uma área for conhecida, os gradientes de gravidade daquela superfície podem ser calculadas, se a densidade for conhecida. 
(A)

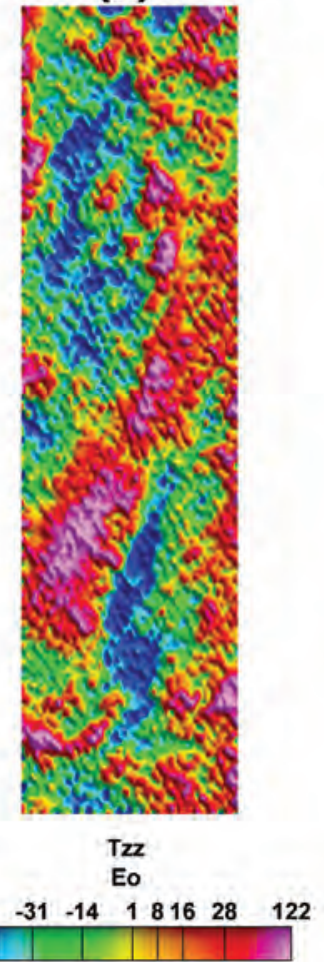

(B)

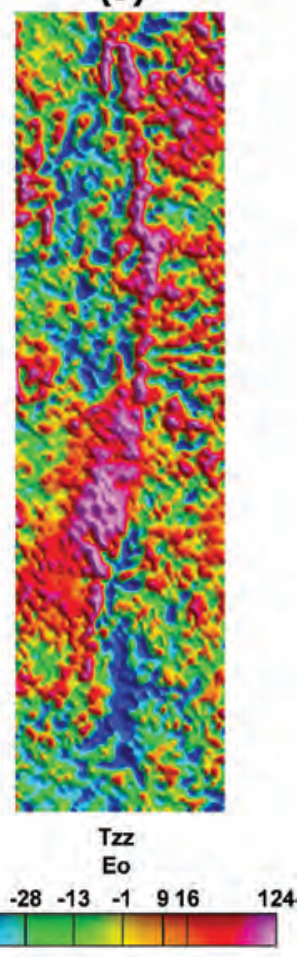

Figura 17 - (A) Mapa da componente $T_{z z}$ do tensor de aerogradiometria gravimétrica da região do Baú-Gandarela, corrigida da influência topográfica usando modelo definido pela topografia SRTM para uma densidade de $2,7 \mathrm{~g} / \mathrm{cm}^{3}$. (B) Mapa da componente $T_{z z}$ do tensor de aerogradiometria gravimétrica da região do Baú-Gandarela, corrigida da influência topográfica usando modelo definido pela topografia a laser para uma densidade de $2,7 \mathrm{~g} / \mathrm{cm}^{3}$.

Em áreas com densa cobertura vegetal, o terreno fica "invisível". Os dois métodos ativos têm penetrabilidade na vegetação, mas a eficiência desta penetrabilidade varia muito em função das circunstâncias, incluso o tipo de cobertura vegetal.

0 resultado da subtração entre os dois modelos mostra que a diferença na altimetria pode variar de -68 metros até +69 metros, ou seja, pelo menos em um ponto a cota do modelo SRTM está a 68 metros abaixo da cota real, neste caso, tomandose como base o modelo laser, em pelo menos um ponto a cota do modelo SRTM está 69 metros acima da cota do modelo laser.

Como o modelo digital de terreno do SRTM tem uma resolução de 90 metros a interpolação tende a suavizar o MDT, ou seja, os altos topográficos são suavizados e os vales estão mais altos que a realidade. 0 modelo laser por apresentar uma resolução de 1 metro ressalta os detalhes com muito mais precisão que 0 modelo SRTM. Conclui-se que as grandes diferenças entre os modelos estão localizados nas encostas, vales e topos.

Durante a análise de correção de densidades, foi possível avaliar o quanto é importante a utilização de um MDT preciso e utilizando diferentes densidades é possível escolher a que meIhor representa a geologia da região. Uma faixa de valores de 1,5 a $4,5 \mathrm{~g} / \mathrm{cm}^{3}$ foi analisada, baseada no conhecimento geológico atual, para determinar o melhor valor de densidade que remove 0 efeito de terreno dos dados de Free-Air medidos. Pretende-se desenvolver um algoritmo mais elaborado que considera diferentes densidades na mesma malha regular e não faixas de valores aplicados a uma região de estudo.

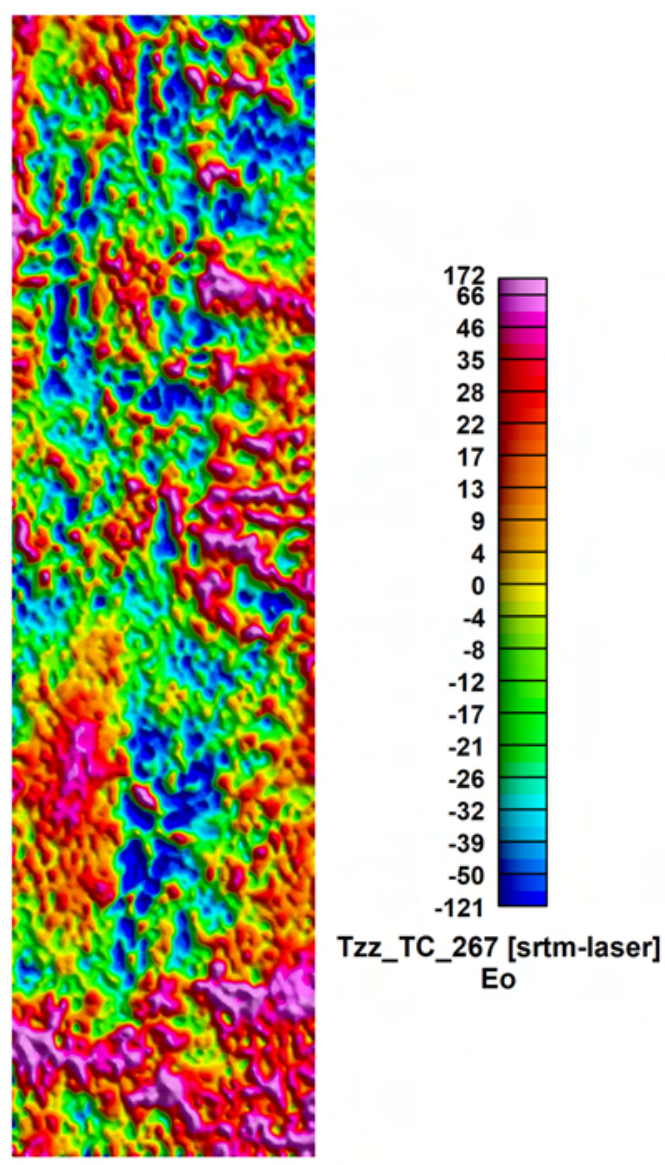

Figura 18 - Mapa da diferença entre a componente $T_{z z}$ corrigida do terreno do SRTM e da componente $T_{z z}$ corrigida do terreno a laser. Os valores negativos (cor azul) representam as regiões onde após a correção de terreno o sinal da gravidade foi subestimado, ou seja, alvos verdadeiros podem ter sido removidos. Os valores positivos (cor magenta) representam as regiões onde após a correção de terreno 0 sinal da gravidade foi superestimado, pois a mesma foi feita com 0 modelo digital de terreno do SRTM, ou seja, falsos alvos podem ter sido criados.

A densidade que melhor representou a geologia da região foi 0 valor de $2,7 \mathrm{~g} / \mathrm{cm}^{3}$ pois delimitou perfeitamente a formação ferrífera e os corpos de hematita da área do Baú-Gandarela. A mesma densidade aplicada aos dados de MDT do SRTM apresentaram falsas anomalias para prospecção de hematita e os alvos verdadeiros não apareceram no mapa. 


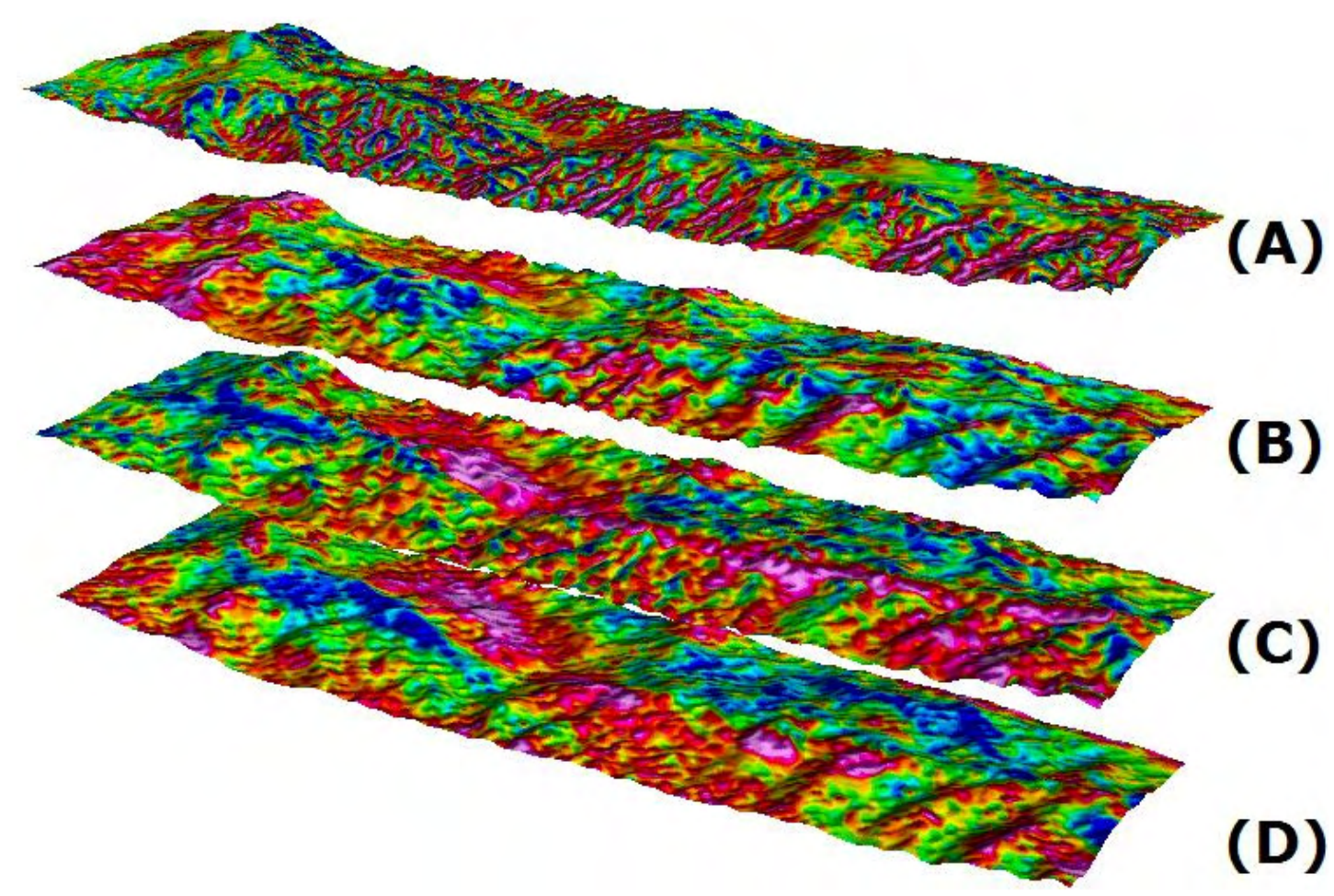

Figura 19 - (A) Diferença entre as topografias SRTM e laser. Os valores positivos (cor magenta) representam as regiões onde após a correção de terreno 0 sinal da gravidade foi superestimado, ou seja, falsos alvos podem ter sido criados. (B) Diferença entre as malhas regulares das componentes $T_{z z}$ calculadas com densidade de 2,67 $\mathrm{g} / \mathrm{cm}^{3}$ obtidas das correções de terreno com SRTM e laser. Os valores negativos (cor azul) representam as regiões onde após a correção de terreno 0 sinal da gravidade foi subestimado, ou seja, alvos verdadeiros podem ter sido removidos. (C) Malha regular da componente $T z z$ corrigida com a densidade de $2,67 \mathrm{~g} / \mathrm{cm}^{3} \mathrm{e}$ com modelo digital de terreno a laser. (D) Malha regular da componente $T z z$ corrigida com a densidade de $2,67 \mathrm{~g} / \mathrm{cm}^{3}$ e com modelo digital de terreno do SRTM.

Nas correções realizadas com as densidades de 3,2, 3,7 e $4,2 \mathrm{~g} / \mathrm{cm}^{3}$ dos dados corrigidos com o MDT do SRTM a formação ferrífera não está mais presente. Na correção realizada com 0 MDT a laser 0 alvo principal para a prospecção de hematita permanece, porém, os sinais de overcorrection estão presentes nas rochas encaixantes.

Os dados de aerogradiometria gravimétrica corrigidos com o modelo digital de terreno do SRTM causaram imprecisões no resultado da componente $T_{z z}$, ou seja, refletiu diretamente na interpretação da geologia da região, na avaliação do potencial mineral da área e nas ações de pesquisa e exploração.

\section{AGRADECIMENTOS}

Os autores agradecem à Vale S.A., especialmente à Diretoria de Ferrosos pela oportunidade de publicação deste trabalho.

\section{REFERÊNCIAS}

BRIGGS IC. 1974. Machine Contouring using Minimum Curvature. Geophysics, 39(1): 39-48.
DORR JVN. 1969. Physiographic stratigraphic and structural development of the Quadrilátero Ferrífero, Minas Gerais, Brazil. Washington, DNPM/USGS, Prof. Paper 641-A, $109 \mathrm{p}$.

FARR TG, ROSEN PA, CARO E, CRIPPEN R, DUREN R, HENSLEY S, KOBRICK M, PALLER M, RODRIGUEZ E, ROTH L, SEAL D, SHAFFER S, SHIMADA J, UMLAND J, WERNER M, OSKIN M, BURBANK D \& ALSDORF D. 2007. The Shuttle Radar Topography Mission. Reviews of Geophysics, 45(2): 21-35.

GROHMANN CH, RICCOMINI C \& STEINER SS. 2008. Aplicações dos Modelos de Elevação SRTM em Geomorfologia. Revista Geográfica Acadêmica, 2(2): 73-83.

PINHEIRO ES. 2006. Comparação entre Dados Altimétricos Shuttle Radar Topography Mission, Cartas Cartográficas e GPS: numa área com relevo escarpado. Revista Brasileira de Cartografia, 58(1): 1-9.

WOLOBAH S. 2007. Geophysics Exploration using Gravity Gradients. African Institute for Mathematical Sciences (AIMS). Master of Science Thesis. $40 \mathrm{p}$. 


\section{NOTAS SOBRE OS AUTORES}

Marco Antonio Braga. Doutor e Mestre em Geologia com ênfase em Geofísica Aplicada pela Universidade Federal do Rio de Janeiro/Colorado School of Mines em 2009. Especialista em métodos geofísicos aplicados à exploração de minério de ferro. Atualmente é coordenador de geofísica da área de Ferrosos da Vale.

Dionísio Uendro Carlos. Bacharel e Mestre em Geofísica pelo IAG/USP, respectivamente em 2002 e 2006. Especialista em aerogamaespectrometria, tendo desenvolvido os primeiros blocos transportáveis de concreto radioativo para calibração de detectores gama portáteis e aerotransportados da América Latina. Trabalha na Vale, na Gerência de Exploração de Ferrosos, realizando processamento e inversão de dados 3D-FTG e aeromagnetometria. Desenvolve doutorado em aerogradiometria gravimétrica no Observatório Nacional/MCT.

Rodrigo Rocha Sousa. Técnico em Geologia \& Mineração pelo CEFET-RN no ano de 2003. Tendo especialização em SIG, atualmente trabalha para a Vale na Gerência de Exploração de Ferrosos.

Henry Galbiatti. Mestre em Geologia Estrutural e Mestre em Geotecnia pela Universidade Federal de Ouro Preto. Atualmente é Gerente de Exploração Mineral de Ferrosos da Vale.

Tiago de Almeida. Mestrando em Geofísica Aplicada pela UFRGS. É especialista em métodos geofísicos aplicados ao minério de ferro. 